\title{
Efeitos dos dutos troposféricos em sinais GPS
}

\author{
Gláucia Costa Balvedi e Fernando Walter
}

\begin{abstract}
Resumo - A propagação de sinais GPS provenientes de satélites com baixa elevação em dutos troposféricos é simulada através de dois métodos: óptica geométrica e óptica física. Os dutos troposféricos são geralmente ignorados na modelagem do canal satélite/receptor devido ao fato dos ângulos de elevação envolvidos serem, em geral, elevados. Na situação considerada neste trabalho os ângulos de elevação são pequenos $\left(<5^{\circ}\right)$, situação na qual os mecanismos de propagação anômala são dominantes na presença de dutos e não podem ser descartados. As simulações permitem observar a potência e o ângulo de elevação do sinal confinado no duto. Análises são feitas para estudar o efeito de dutos na recepção de sinais GPS.
\end{abstract}

Palavras - Chave - Dutos troposféricos; Sistemas de Navegação Global; Propagação de ondas; Métodos numéricos.

\begin{abstract}
Low elevation GPS signals propagation in tropospheric ducts is simulated making use of two: geometrical and physical optics. Tropospheric ducts are often forgotten in satellite-Earth links modeling because the elevation angles involved are usually large. For the low elevation angle considered in this work the mechanisms of anomaly propagation are dominant and cannot be ignored. In the simulations run the power and elevation of the confined signals can be observed and the possibility of positioning error occurrences due to the presence of ducts in the satellite-Earth link is verified.
\end{abstract}

Keywords - Tropospheric ducts; Global Navigation Systems; Electromagnetic propagation; Numerical methods.

\section{INTRODUÇÃO}

Os mecanismos de propagação troposférica são alvos de pesquisas há bastante tempo, visto que os enlaces de microondas e radares, bem como outros sistemas de comunicação, utilizam-se da troposfera como meio de transmissão. O modo pelo qual os fenômenos climáticos (chuvas, variação de temperatura e umidade) afetam a propagação de ondas necessitam ser conhecidos para que se faça um correto dimensionamento desses sistemas.

Um dos fenômenos que ocorre na troposfera é o denominado duto troposférico, que possui a capacidade de confinar ondas eletromagnéticas de maneira semelhante a um guia de ondas e propagá-las a distâncias bem maiores do que atingiriam sem a presença dos mesmos. São capazes de guiar sinais com baixos ângulos de elevação e quanto maior a freqüência de operação maior a probabilidade dos dutos confinarem a onda eletromagnética [1]. Pelo fato dos receptores GPS encontrarem-se na troposfera é necessário conhecer o comportamento dos sinais provenientes dos satélites ao atravessarem esta camada.

Gláucia Costa Balvedi e Fernando Walter, Laboratório GNSS, Divisão de Engenharia Eletrônica, ITA - Instituto Tecnológico de Aeronáutica, São José dos Campos, SP, Brasil. E-mails: balvedi@ita.br; fw2@ita.br. Este trabalho é financiado pela FINEP (Convênio 1825/04, Contrato 01.05.0154.00).
Duas hipóteses podem ser consideradas ao investigar a possibilidade dos dutos troposféricos trazerem problemas ao cálculo da posição do usuário GPS. São elas: 1) a potência do sinal confinado no duto troposférico pode ultrapassar a potência do sinal entrante na troposfera devido principalmente a interferências construtivas e o nível de potência pode ser alto o suficiente para causar saturação/interferências no receptor; 2) o sinal captado pelo receptor pode alcançá-lo com um ângulo "aparente" tal como se fosse proveniente de um satélite com uma elevação maior.

O objetivo deste trabalho é estudar o comportamento dos sinais GPS com baixo ângulo de elevação guiados por dutos troposféricos. Através de simulações é possível observar se as duas hipóteses citadas anteriormente ocorrem e, em caso positivo, analisa-se então se realmente são capazes de ocasionar problemas no processamento dos sinais pelo receptor. Para realizar as simulações é necessário utilizar-se de métodos de predição eletromagnética [2]. O traçado de raios (óptica geométrica) fornece informações qualitativas a respeito da frente de onda, inclusive permitindo observar o comportamento do raio ao longo de toda a trajetória de interesse. $\mathrm{O}$ método das equações parabólicas (óptica física) permite o cálculo da potência a confinada no duto.

\section{CARACTERÍSTICAS DO GPS}

O GPS (Global Positioning System) foi projetado de forma a atender inúmeros usuários distribuídos pelo globo terrestre. A antena do satélite é projetada de modo a cobrir a máxima área possível e de maneira a não interferir em outros sistemas de comunicação, portanto a potência recebida na Terra deve estar abaixo do ruído local. Cada satélite transmite, na freqüência L1 (1575,42 MHz), um código binário que o identifica (código C/A), e o tempo de trânsito do sinal é calculado através da correlação do sinal recebido com sua réplica gerada no receptor. O nível mínimo especificado de potência recebida para o código C/A em L1 é de -160 dBw [3, 4].

Quatro a onze satélites da constelação GPS podem ser recebidos simultaneamente por um usuário, sendo que um ou mais podem estar no horizonte (com baixa elevação, menor que $5^{\circ}$ ). O receptor GPS trabalha com uma máscara de recepção, fazendo com que satélites mais próximos ao horizonte sejam descartados do cálculo da posição do usuário. A antena do receptor em geral é projetada de forma a ter baixos ganhos para sinais com pequenos ângulos de elevação (característica que ajuda a diminuir os efeitos de multicaminho, visto que os sinais refletidos atingem o receptor com ângulos baixos na maioria dos casos) como ilustra a Fig. 1.

Os correlatores do receptor terão em suas saídas não somente as correlações dos códigos C/A desejados, mas também as correlações cruzadas com todos os demais satélites em vista, mesmo aqueles que estão abaixo da máscara, que 
passam a agir como interferência ao rastreamento do sinal desejado. Em situações normais a presença de satélites no horizonte não traz grandes problemas ao cálculo da posição do usuário. $\mathrm{O}$ receptor gera réplicas dos códigos PRN dos satélites desejados e o pico de correlação cruzada do sinal do satélite com baixo ângulo de elevação (não desejado) com as réplicas é baixo (quando todos os sinais que atingem o receptor possuem o mesmo nível de potência). Mas quando sinais fortes e fracos estiverem presentes simultaneamente há a possibilidade de interferirem um nos outros, pois um pico de correlação cruzada pode ser mais forte que $o$ de autocorrelação [6]. Para se evitar interferências todos os sinais devem ter aproximadamente o mesmo nível de potência, evitando assim falsas aquisições [7].

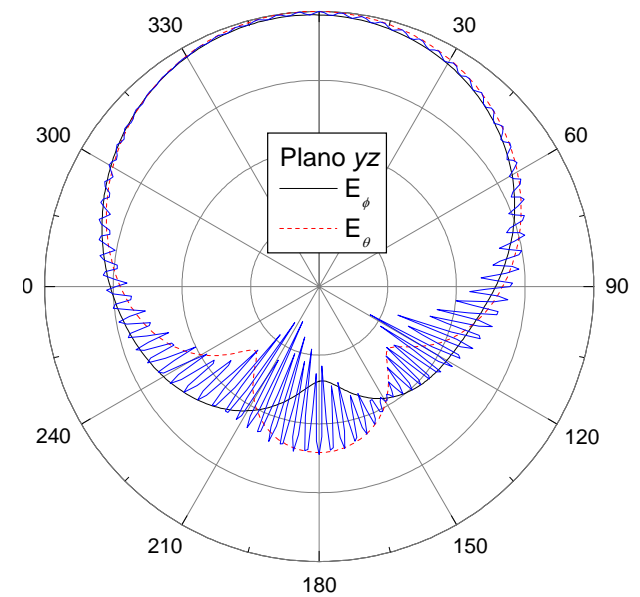

Fig. 1: Diagrama de elevação da antena receptora (circularmente polarizada à direita). $\mathrm{O}$ ganho da antena varia de $0 \mathrm{~dB}$ no zênite $(\theta=0)$ até $-10 \mathrm{~dB}$ no horizonte $(\theta=90,270)$ [5].

\section{DUTOS TROPOSFÉRICOS}

Dutos troposféricos são associados à ocorrência de gradientes anormais da refratividade troposférica $N$, a qual é definida por:

$$
N=(n-1) \cdot 10^{6}
$$

onde $n$ é o índice de refração.

Um gradiente é considerado normal se estiver entre -0,079 e $0 \mathrm{Nm}^{-1}$. Para que se formem os dutos gradientes menores que $-0,157 \mathrm{Nm}^{-1}$ devem ocorrer. Para facilitar a identificação de dutos troposféricos e também realizar a transformação de Terra esférica para plana é definido o índice de refratividade modificado $M$, dado por:

$$
M=N+0,157 \cdot h
$$

sendo $h$ a altura em metros.

Este índice possui seu gradiente $\left(\mathrm{Mm}^{-1}\right)$ negativo para gradientes de refratividade $\left(\mathrm{Nm}^{-1}\right)$ menores que $-0,157$ [8].

Dutos podem ser de dois tipos: de superfície ou elevado. $\mathrm{O}$ primeiro surge quando uma camada com gradiente de $M$ negativo surge próxima à superfície (Figs. 2 e 3), o segundo quando uma camada com gradiente de $M$ negativo está elevada o bastante de forma que $M$ no topo desta camada seja maior que o valor de $M$ da superfície (Fig. 4).

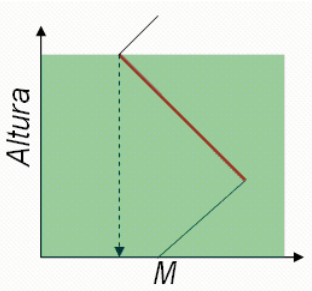

Fig. 2: Duto de superfície (região em verde). O valor de $M$ no topo da camada com gradiente negativo (reta vermelha) é menor que o valor de $M$ na superfície.

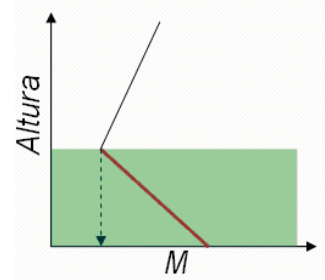

Fig. 3: Duto de evaporação (região em verde), tipo especial de duto de superfície. O valor de $M$ no topo da camada com gradiente negativo (reta vermelha) é menor que o valor de $M$ na superfície.

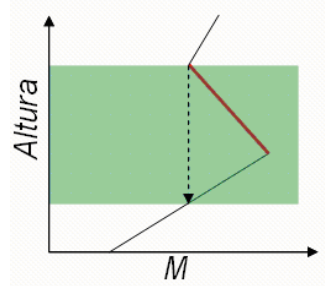

Fig. 4: Duto elevado (região em verde). A camada com gradiente negativo (reta vermelha) está elevada o bastante, de forma que o valor de $M$ no topo da camada é maior que o valor de $M$ na superfície.

\section{MODELOS DE PREDIÇÃO}

\section{A. Traçado de raios}

O traçado de raios é um método qualitativo baseado na lei de Snell $[9,10]$, que permite determinar a trajetória da onda (energia) através de aplicações sucessivas da eq. (3):

$$
\begin{aligned}
& \beta=\alpha+\left(d r \cdot \frac{\partial m}{\partial z}\right) \\
& z^{\prime}=z_{1}+\frac{\left(\beta^{2}-\alpha^{2}\right)}{\left(2 \cdot \frac{\partial m}{\partial z}\right)}
\end{aligned}
$$

onde $m$ é definido por:

$$
m=M \cdot 10^{-6}+1
$$

Considerando-se as condições iniciais altura e ângulo do raio $\left(z_{1}\right.$ e $\alpha$, respectivamente) pode-se calcular o ângulo $\beta$ que o raio terá na altura $z^{\prime}$ (ver Fig. 5). O tamanho do passo $(d r)$ é 
um dos parâmetros definidos pelo usuário.

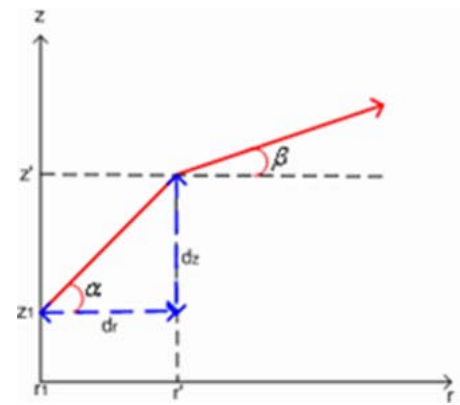

Fig. 5: Traçado de raios em uma atmosfera horizontalmente estratificada.

\section{B. Equações parabólicas}

O método das equações parabólicas consiste basicamente em, a partir da equação de onda escalar tridimensional (5),

$$
\nabla^{2} \Psi+k^{2} n^{2} \Psi=0
$$

onde $\Psi$ pode ser separada em uma função de amplitude e fase:

$$
\Psi=u(x, z) e^{i k x}
$$

chegar à uma equação parabólica (7) através do uso de simetrias e aproximações que podem ser aplicadas a propagação troposférica à pequenas elevações $[11,12,13]$ :

$$
\frac{\partial^{2} u}{\partial z^{2}}+2 i k \frac{\partial u}{\partial x}+k^{2}\left(m^{2}-1\right) u=0
$$

Um método numérico é então utilizado de forma a solucionar a eq. (7). A solução numérica da equação parabólica é fornecida pelo método "Split-Step" Fourier [14], de onde se obtém:

$$
u(x+\Delta x, z)=e^{\frac{i k \Delta x\left(m^{2}-1\right)}{2}} \mathfrak{J}^{-1}\left\{e^{\frac{-i \Delta x p^{2}}{2 k}} \mathfrak{J}\{u(x, z)\}\right\}
$$

A eq. (8) é diretamente implementada em computador através do uso de FFTs. Trata-se de um problema de contorno aberto, tal como ilustra a Fig. 6. O contorno inferior $(z=0)$ representa a superfície sobre a qual a onda se propaga, o contorno esquerdo $(x=0)$ representa os valores iniciais do campo (campo incidente no duto) necessários para o início da integração computacional $[15,16]$.

\section{MODELAGEM E SIMULAÇÕES}

\section{A. Modelagem da propagação em dutos}

Os resultados obtidos pelo método de traçado de raios derivam do conjunto de eqs. (3). Um programa em Matlab ${ }^{\circledR}$ foi desenvolvido onde a trajetória de cada raio foi calculada, sendo fornecidos os dados iniciais de cada raio, isto é, o ângulo de elevação e a altura.

$\mathrm{O}$ método das equações parabólicas foi utilizado para efetuar o cálculo da potência do sinal GPS na troposfera na presença de dutos. A base da implementação computacional é a eq. (8), sendo que o usuário define a distância e altura máxima a ser analisada. Aspectos computacionais referentes à implementação (condições de contorno, coeficientes de reflexão, tamanho dos passos, entre outros) necessitam ser conhecidos $[16,17]$.

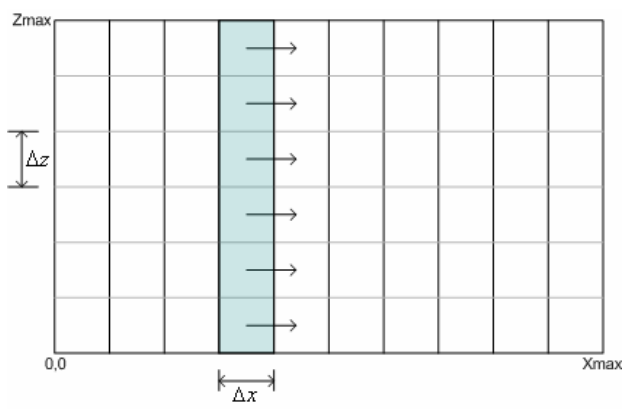

Fig. 6: Domínio da solução para a equação parabólica bidimensional (contorno aberto). A solução do campo em $(x+\Delta x)$ e função do campo em $(x)$, fazendo com que o algoritmo "Split-Step" Fourier seja eficiente para contornos simples.

A condição inicial de campo são valores dos campos oriundos de um determinado satélite: uma onda plana circularmente polarizada à direita [18]. Pode-se desejar analisar como uma onda refletida no solo antes de atingir o duto interage com uma onda que atinge o duto vinda diretamente do satélite. O campo direto deve então ser somado ao refletido na condição inicial de campo (contorno esquerdo), como ilustra a Fig. 7:

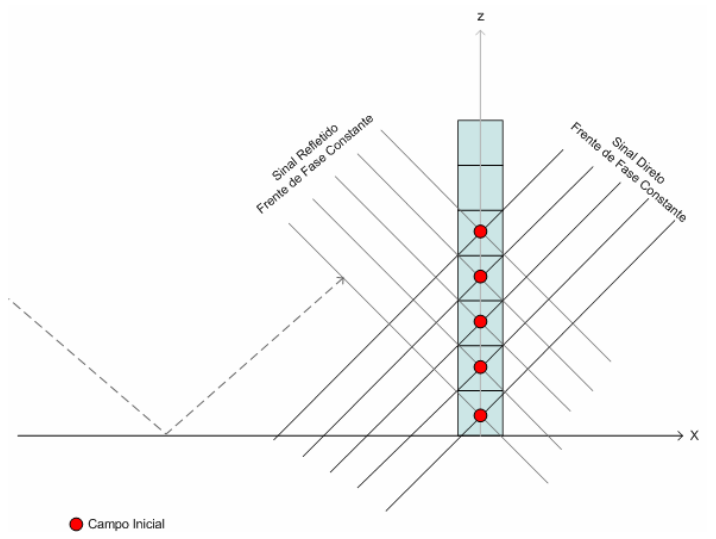

Fig. 7: Representação das frentes de onda dos sinais direto e refletido no solo antes de atingir o duto troposférico (condição inicial de campo).

\section{B. Simulações}

As simulações foram realizadas utilizando-se os perfis de dutos troposféricos encontrados na literatura, considerando-se duas situações: na primeira, apenas o sinal direto do satélite está presente no contorno esquerdo; na segunda, tanto o sinal direto como o refletido estão presentes. O contorno inferior foi aproximado como uma superfície condutora. Esta simplificação na condição de contorno inferior é possível porque o objetivo é simular a propagação de sinais GPS sobre 
a água do mar, onde é maior a ocorrência de dutos troposféricos (considerando-se oceano calmo, sem perdas e para a freqüência $\mathrm{L} 1$, a água do mar pode ser aproximada como um condutor perfeito). O satélite possui baixa elevação, ou seja, está se pondo ou aparecendo no horizonte. O campo inicial foi normalizado de forma a apresentar $-160 \mathrm{dBw}$ na entrada do duto. Em todas as simulações, os raios incidentes atingem o duto troposférico no contorno esquerdo (definido como alcance $=0$ ) Os raios se propagam da esquerda para a direita.

O primeiro grupo de simulações representa a propagação do sinal GPS em uma atmosfera padrão, que é um modelo que apresenta propriedades semelhantes à atmosfera local, sendo a mais usada em estudos de propagação em microondas a denominada atmosfera 4/3, que apresenta um decréscimo linear da refratividade em função da altura dado por [8]:

$$
d N / d h=-0,039 / m
$$

O perfil de $M$ para uma atmosfera padrão está ilustrado na Fig. 8. O traçado de raios para esse perfil, considerando apenas o sinal direto proveniente do satélite GPS, está ilustrado na Fig. 9. As Figs. 10 e 11 ilustram as simulações utilizando o método das equações parabólicas.

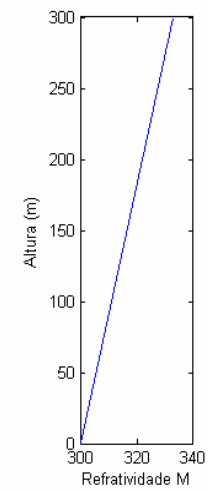

Fig. 8: Perfil da refratividade modificada $M$ para atmosfera padrão $(M$ cresce com a altura).

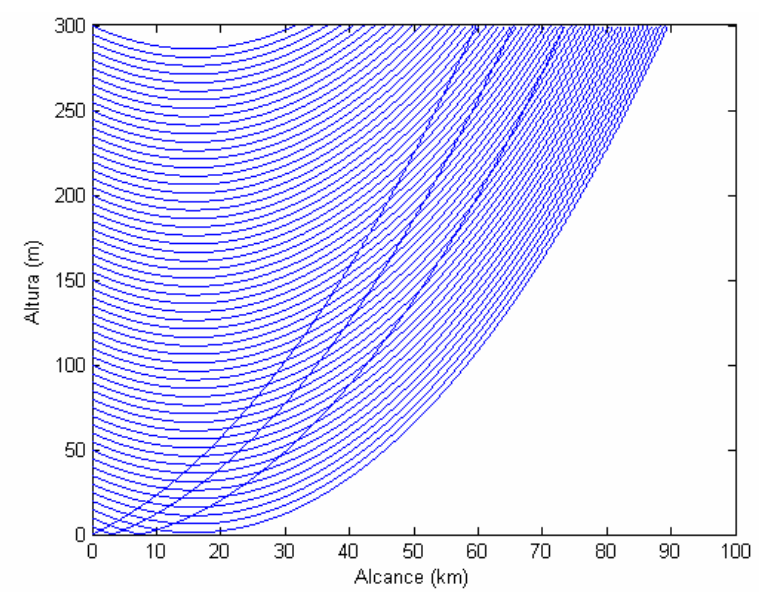

Fig. 9: Traçado de raios para atmosfera padrão, considerando apenas sinal direto proveniente do satélite GPS.

O segundo grupo de simulações representa a propagação do sinal GPS em um duto troposférico de $30 \mathrm{~m}$ de altura, cujo perfil de $M$ está ilustrado na Fig. 12. O perfil de $M$ decresce até atingir $30 \mathrm{~m}$ de altura, depois cresce tal como numa atmosfera padrão (4/3). A Fig. 13 ilustra o traçado de raios considerando apenas o sinal direto proveniente do satélite GPS. Comparando esta simulação com a apresentada na Fig. 9 pode-se notar confinamento dos raios entre 0 e $30 \mathrm{~m}$ de altura. As Figs. 14 e 15 apresentam as simulações para o duto de $30 \mathrm{~m}$ de altura utilizando o método das equações parabólicas. Na Fig. 14, considera-se o sinal direto, e na Fig. 15, o direto e o refletido. A maior quantidade de raios confinados entre 0 e $30 \mathrm{~m}$ de altura se traduz em potência confinada nesta região.

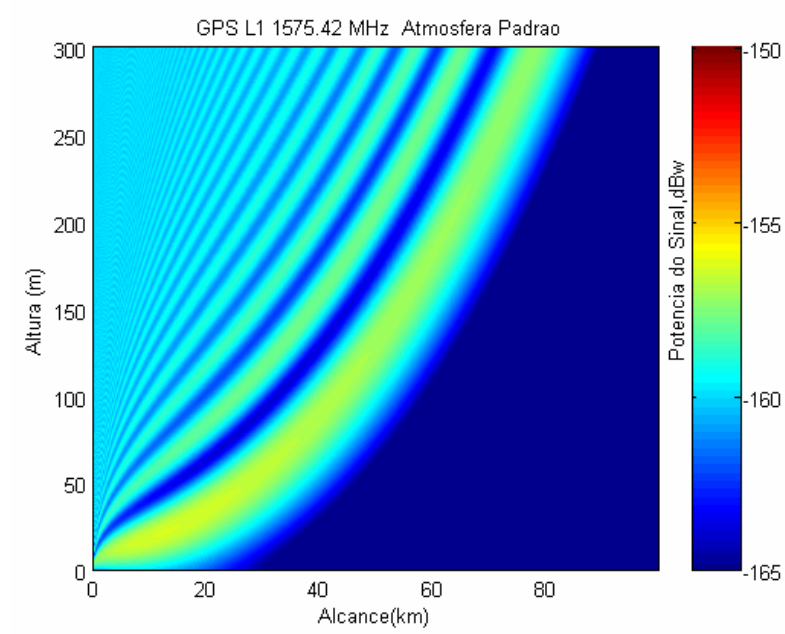

Fig. 10: Método das equações parabólicas - sinal direto. Atmosfera padrão. Ao lado das simulações, barra vertical de cores com a escala de potência do campo em dBw.

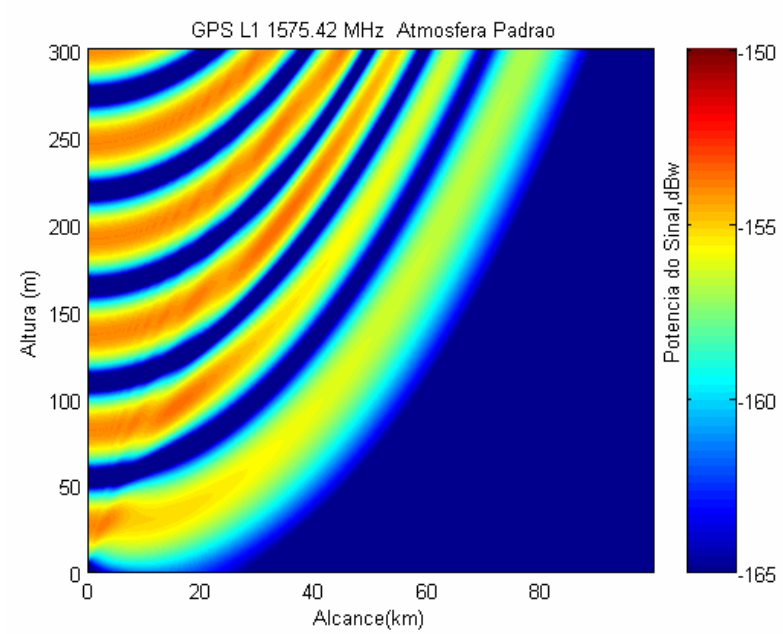

Fig. 11: Método das equações parabólicas - sinal direto e refletido. Atmosfera padrão. Ao lado das simulações, barra vertical de cores com a escala de potência do campo em dBw.

O terceiro grupo de simulações representa a propagação do sinal GPS em um duto troposférico elevado entre 50 e $200 \mathrm{~m}$ altura, cujo perfil de $M$ está ilustrado na Fig. 16. O perfil de $M$ é negativo entre 150 e $200 \mathrm{~m}$ de altura, depois cresce tal como numa atmosfera padrão. A Fig. 17 ilustra o traçado de raios considerando apenas o sinal direto proveniente do satélite GPS. Mais uma vez pode-se verificar os raios confinados na região do duto troposférico (entre 50 e $200 \mathrm{~m}$ de altura). As Figs. 18 e 19 apresentam as simulações para o duto elevado entre 50 e $200 \mathrm{~m}$ de altura utilizando o método das equações 
parabólicas. Na Fig. 18, considera-se o sinal direto, e na Fig. 19, o direto e o refletido. Pode-se observar a energia confinada na região do duto troposférico (entre 50 e $200 \mathrm{~m}$ de altura).

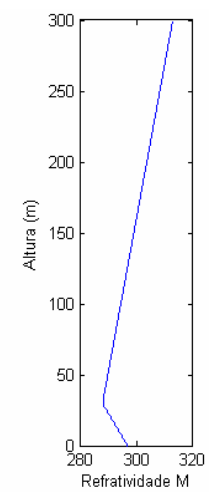

Fig. 12: Perfil da refratividade modificada $M$ para duto de evaporação de 30 $\mathrm{m}$ de altura.

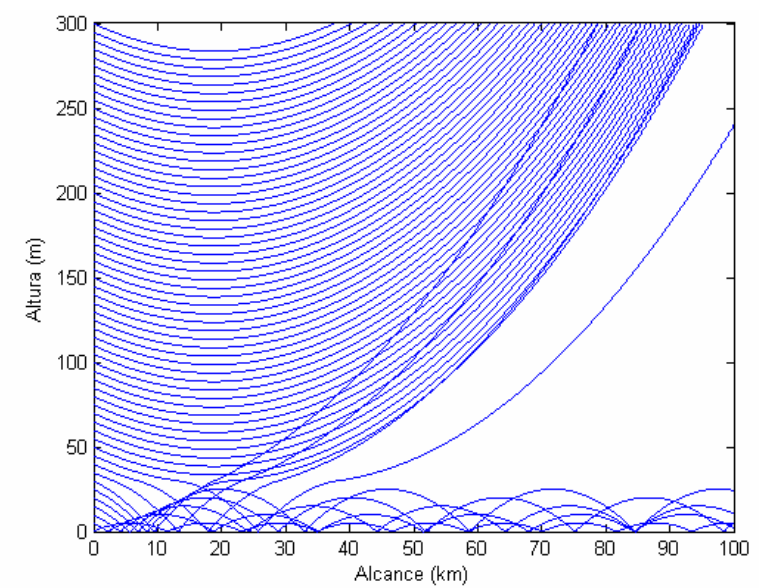

Fig. 13: Traçado de raios para duto de evaporação de $30 \mathrm{~m}$ de altura. Nota-se presença de raios confinados entre 0 e $30 \mathrm{~m}$ de altura

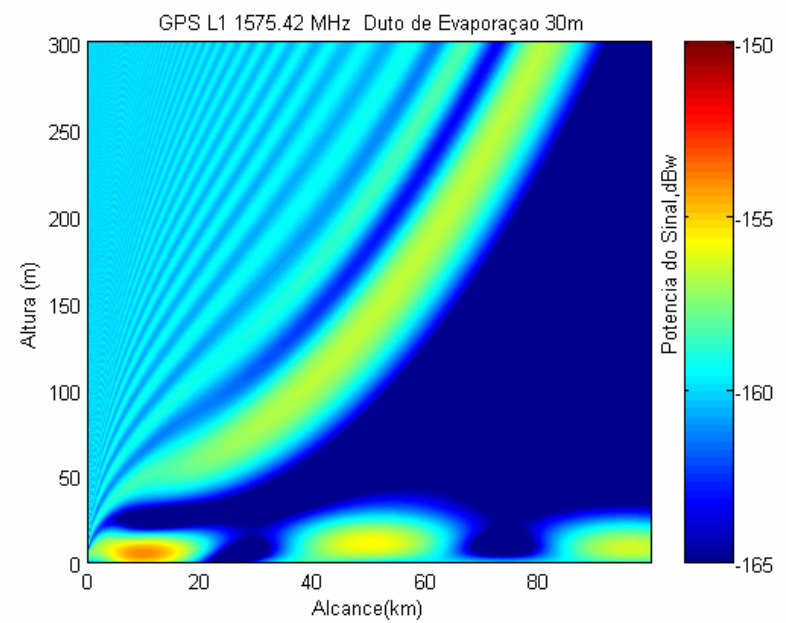

Fig. 14: Método das equações parabólicas - sinal direto. Duto de evaporação de $30 \mathrm{~m}$ de altura. Ao lado das simulações, barra vertical de cores com a escala de potência do campo em dBw.

\section{CONCLUSÕES}

O comportamento do sinal proveniente de um satélite GPS com baixa elevação em dutos troposféricos foi analisado através de dois métodos numéricos: traçado de raios e equações parabólicas. Pode-se agora analisar se os dois fatores mencionados na introdução podem ou não ocasionar problemas ao cálculo da posição do usuário.

Com relação à potência confinada no duto, pode-se dizer que é possível que o sinal confinado no duto sature o receptor GPS, porém isto não ocorrerá com freqüência. Como observado nas simulações apresentadas, o sinal confinado é da ordem de $-150 \mathrm{dBw}$, portanto dentro da faixa dinâmica do receptor. Somente em casos extremos a faixa dinâmica diminuirá a ponto da potência confinada saturar o receptor [7].

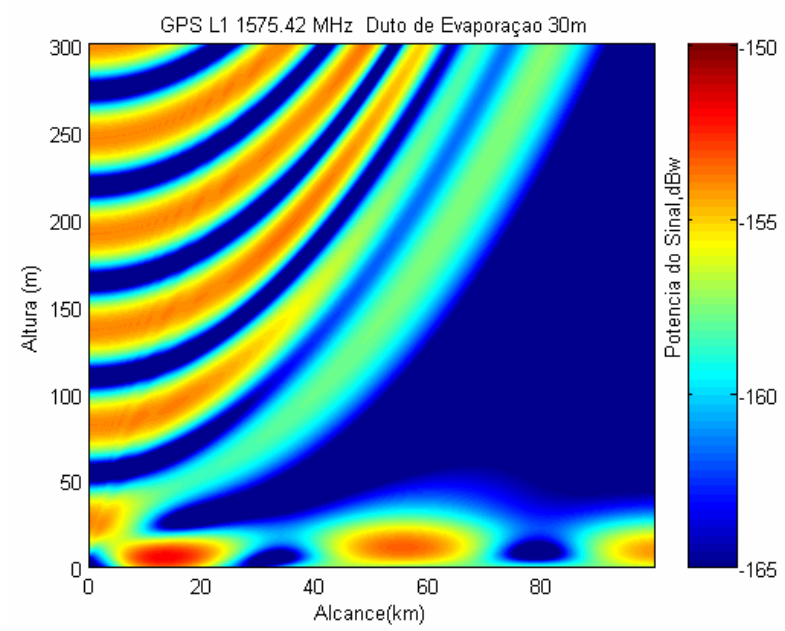

Fig. 15: Método das equações parabólicas - sinal direto e refletido. Duto de evaporação de $30 \mathrm{~m}$ de altura. Ao lado das simulações, barra vertical de cores com a escala de potência do campo em $\mathrm{dBw}$.

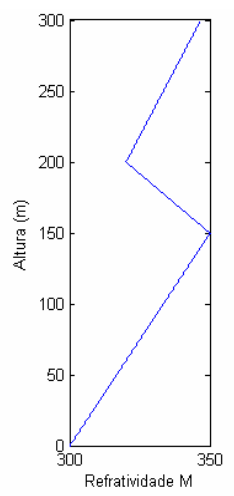

Fig. 16: Perfil da refratividade modificada $M$ para duto elevado entre 50 e $200 \mathrm{~m}$ de altura.

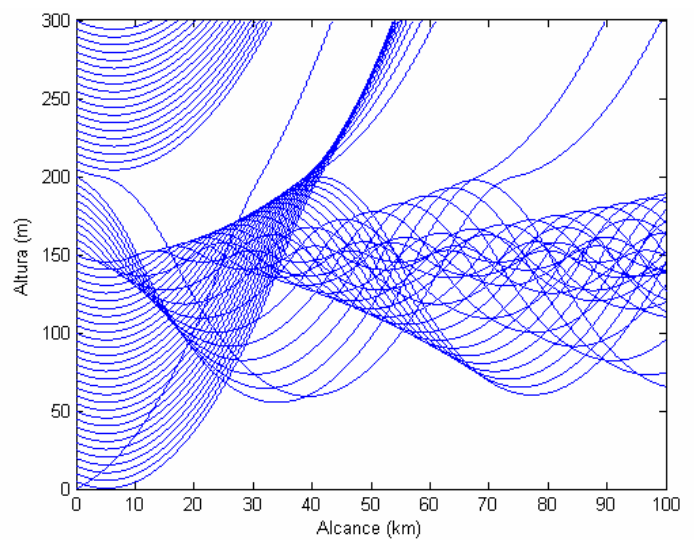

Fig. 17: Traçado de raios para duto elevado entre 50 e $200 \mathrm{~m}$ de altura. 


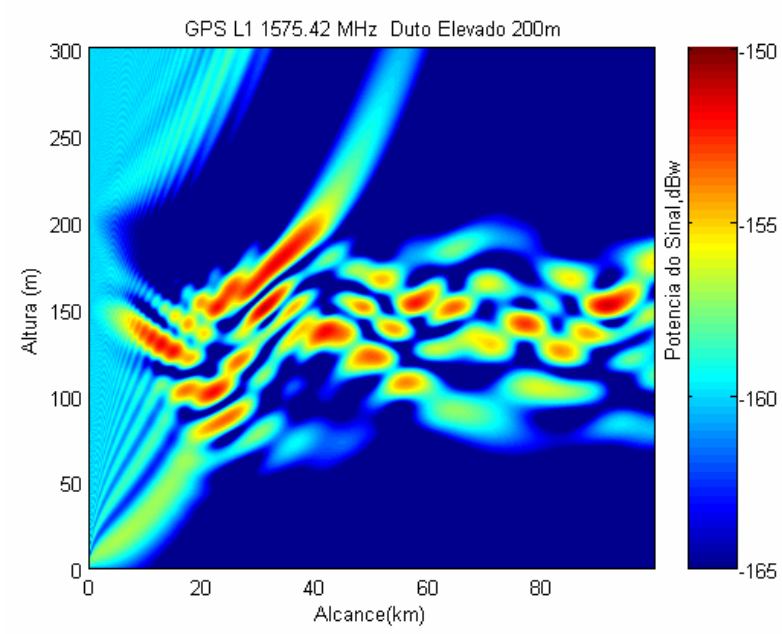

Fig. 18: Método das equações parabólicas - sinal direto. Duto elevado entre 50 e $200 \mathrm{~m}$ de altura. Ao lado das simulações, barra vertical de cores com a escala de potência do campo em $\mathrm{dBw}$.

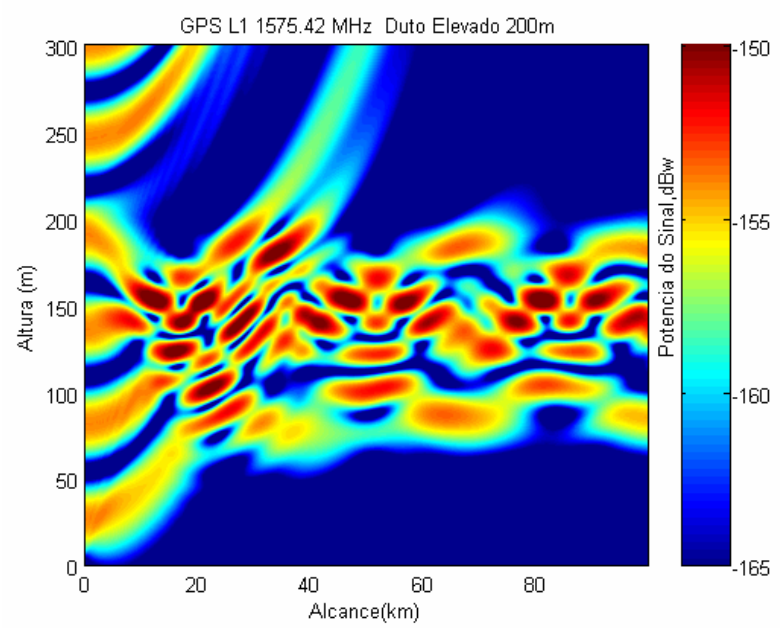

Fig. 19: Método das equações parabólicas - sinal direto e refletido. Duto elevado entre 50 e $200 \mathrm{~m}$ de altura. Ao lado das simulações, barra vertical de cores com a escala de potência do campo em $\mathrm{dBw}$.

Já o ângulo de elevação do sinal confinado no duto deve ser mais bem analisado. Como ilustra a Fig. 1, o ganho da maioria das antenas GPS receptoras comuns varia cerca de 10 $\mathrm{dB}$ do zênite ao horizonte. Um sinal com alto ângulo de elevação terá maior ganho do que se tivesse com baixo ângulo de elevação. No caso dos sinais confinados isto poderá trazer problemas, pois a alta potência atingida pelo confinamento somar-se-ia ao aumento de ganho provocado pela antena receptora, pois como se vê nos gráficos de traçados de raios os mesmos podem adquirir elevações altas em certos pontos. O sinal confinado (não desejado) ficaria com maior potência do que o sinal desejado, levando a aquisições incorretas. Portanto é possível que a elevação dos raios confunda o receptor levando a falsas aquisições, porém uma situação como esta não duraria muito tempo visto que os satélites não permanecem muito tempo no horizonte (o satélite GPS percorre cerca de $1^{\circ}$ em 3 minutos). Em situações críticas como pouso e aproximação de aeronaves falsas aquisições poderiam inviabilizar a utilização do sistema GPS [17]. Vale ressaltar que vários aeroportos importantes estão muito próximos ao oceano (regiões com maior probabilidade de ocorrência de dutos), como ilustra a Fig. 20:

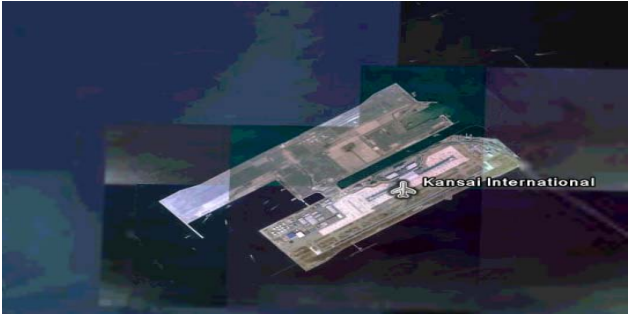

Fig. 20: Aeroporto de Kansai (Japão), totalmente envolto por água do mar. Fonte: Google Earth.

Importante salientar que estes métodos de predição também podem ser utilizados para se analisar a propagação de sinais de outros sistemas de navegação por satélite, tais como GLONASS e Galileo.

\section{REFERÊNCIAS}

[1] D. C. Livingston. Physics of microwave propagation. Prentice Hall, 1970.

[2] M.P Hall, L. W. Barclay and M. T. Hewitt. Propagation of radiowaves. The Institution of Electrical Engineers, 1996.

[3] P. Misra and P. Enge. Global Positioning System: signals, measurements and performance. Ganga-Jamuna Press, 2001.

[4] J. B. Y. Tsui. Fundamentals of Global Positioning Systems receivers: a software approach. Wiley, 2000.

[5] D. C. M. Maciel. Redes de antenas de microfita circularmente polarizadas com apontamento de feixe e controle de nivel dos lóbulos secundários. Tese de mestrado. Instituto Tecnológico de Aeronáutica, 2005.

[6] E. D. Kaplan. Understanding GPS principles and applications. Artech House, 1996.

[7] D. Zandonadi Jr. Superação do problema near/far em pseudosatélites GPS mediante técnica de realimentação do usuário. Tese de doutorado. Instituto Tecnológico de Aeronáutica, 2005.

[8] H. V. Hitney et al. Tropospheric radio propagation assessment. Proc. of the IEEE, v. 73, n. 2, p. 265-283, Fevereiro 1985.

[9] D. E. Kerr. Propagation of short radio waves. McGraw-Hill, 1951.

[10] F. Walter. Nonducted VLF propagation in the magnetosphere. Tese de doutorado. Stanford University, 1969.

[11] K. H. Craig. Propagation modeling in the troposphere: parabolic equation method. Electronic Letters, v. 24, n. 18, p. 1136-1139, Setembro 1988.

[12] K. H. Craig and M. Levy. Parabolic equation modeling of the effects of multipath and ducting on radar systems. IEE Proc.-F, v. 138, n. 2, p. 153-162, Abril 1991.

[13] G. D. Dockery. Modeling electromagnetic wave propagation in the troposphere using the parabolic equation. IEEE Trans. on Antennas and Propagation, v. 36, n. 10, p. 1464-1470, Outubro 1988.

[14] J. R. Kuttler and G. D. Dockery. Theoretical description of the parabolic approximation / Fourier Split Step method of representing electromagnetic propagation in the troposphere. Radio Science, v. 26, n. 2, p. 381-393, Março 1991.

[15] P. L. Slingsby. Modeling tropospheric ducting on VHF/UHF propagation. IEEE Trans. on Broadcasting, v. 37, n. 2, p. 25-34, Junho 1991

[16] B. M. Hannah. Modelling and simulation of GPS multipath propagation. Tese de doutorado. Queensland University of Technology, 2001.

[17] G. C. Balvedi. Efeitos dos dutos troposféricos na propagação e recepção de sinais GPS. Tese de mestrado. Instituto Tecnológico de Aeronáutica, 2006.

[18] B. W. Parkinson and J. J. Spilker Jr. Global Positioning System: theory and applications. American Institute of Aeronautics and Astronautics, 1996. 